\title{
From Research and Practices into Journal Papers: Editor's Insight
}

\author{
Nor Fariza Mohd Nor* \\ Center for Literacy and Sociocultural Transformation \\ Faculty of Social Science and Humanities, \\ Universiti Kebangsaan Malaysia \\ fariza@ukm.edu.my
}

\begin{abstract}
This paper provides guidelines of how to write a robust journal paper. It discusses four important points that an editor-in-chief of a journal considers most: 1) identification of a research problem in the introduction section, which is the key to developing the research objectives and questions, as well as providing the framework or theory/theories to do the research; 2) vigorous literature review as theoretical underpinning and the key to determine the nature of the research; 3) evaluative and critical discussion about how findings are related to the topic or the research discipline; and 4) contribution and novelty of the research. Additionally, language performance in terms of structural and lexical aspects is a significant factor for further review.
\end{abstract}

Keywords-problem
underpinning, critical, evaluative

\section{INTRODUCTION}

The actual process of writing a journal paper is not a linear process for it often a messy and recursive one. This paper describes several key points in writing a journal article. Let me begin by defining the two key terms in the title; practices and research. It is important to define and set the parameters for these two terms before I continue with paper.

Practices refer to the core business that we as teachers and lecturers (educators, henceforth) are engaged in. The core businesses are teaching, marking students' work, facilitating students in the learning process, students' consultations, students' evaluation and other related teaching practices. These practices are usually guided by teachers' beliefs and students' needs. Thus, where does research fit in in relation to practices? Research, in a very general term, is a systematic way for finding things that educators and other people would like to know or do not know, which are referred to as research problems. In this sense, research is a process which begins with how researchers identify and define research problem. Consequently, data obtained from the research contributes to developing our knowledge in a field or study. In sum, research is essentially a problem driven activity.
The next point is the relation between practices and research. I have described in the previous paragraph some of the activities undertaken by educators in the classroom, lectures or tutorials, or seminars. Let us consider some of these activities and see how they can be turned into research. Teaching involves activities, such as teaching reading, writing, speaking and listening. If we consider one, such as reading, what aspects of reading can be turned into research? We can consider the instructional language used in teaching reading, the types of strategies that students employed when they are involved in reading process, student's comprehension (cognitive process), and many more. Likewise, writing involved similar activities as reading. With the ultimate aim of disseminating knowledge to empower students, educators should and are encouraged to reflect on their practices. This generally means educators should think about their underlying values and beliefs about teaching and learning, and to compare these values to classroom practices (Farrell, 2008). Basturkmen (2012) points out that the topic of language teachers' beliefs has attracted considerable research interest and much of this research is based on case studies. When educators are engaged in reflective practices which are based on evidence (systematic collection of data about their classroom practices), educators can articulate to themselves (and others) what they do, how they do it, why they do it, and, ultimately, what the impact of one's teaching is on students' learning. Consequently, engaging in such data-driven reflective practice may mean an affirmation of current practices or the need to make changes to current practices because they may not reflect a teacher's particular beliefs (Farrell \& Ives, 2015). Furthermore, Richardson (2015) points out that conceptions of teaching have shifted from view of teachers as the recipients and consumers of research to the current view of the teacher as producer or mediator of knowledge. This conception has affected research on teaching in terms of what is examined, how the research is conducted and who conducts the research.

\section{KEY POINTS IN WRITING}

Data from your research and practices is the one that you will use to develop and write your journal article. With the wealth of data that you have, what do you write about and how? To begin with, any paper begins with 
identification of a research problem. A research problem is generally defined as a statement about an area of concern, a condition to be improved, a difficulty to be eliminated, or a troubling question that exists in scholarly literature, in theory, or in practice that points to the need for meaningful understanding and deliberate investigation (Bryman, 2007). The research problem is the key to developing the research objectives and questions, in addition to providing the framework or theory/theories to do the research. Research problems can be identified by reading; review past studies, review recent literature, reports or databases on the topic that you are investigating or examining. The 'recommendations for future studies' at the end of journal articles or thesis often suggest potential research. You can also read about theories on the topic and determine if there are theories which can be tested. Bryman (2017) states that research problems range from simple to complex, depending on the number of variables and the nature of their relationship, which will then inform you how to conduct the research. An understanding about the nature of the research will enable you to develop a better solution to the problem. After you have identified the research problem, choose one lens through which to view the research problem, or just look at one facet of it - e.g rather than studying if technology facilitates the process of learning in English, narrow it to whether students perform better when they read online or offline materials. You can still narrow the focus to geographical unit of analysis, i.e the scope.

The first section of a journal article is akin to an essay, which begins with Introduction. Its main function is to contextualize your study, which means that this section serves to set the scene. Imagine a story, whereby you set the setting, main characters and the plot of the story. The introduction showcases the article to readers who are hard pressed for time. These readers will quickly read the introduction section to determine if the content is relevant to their own research interests. The editor-in-chief reads the introduction section to decide if the article has potential for publication or is worth considering. Introduction is about placing your work into the broader research context, and then narrowing your focus to identify specifically what you plan to do in the paper - your research objectives. The broader context will be supported with the literature review. Therefore, introduction should include summaries of important and research which are relevant to your study. This is particularly important if there is an essential or groundbreaking study about the research problem or a key study that refutes or supports your research. In sum, Introduction is about placing your work into the broader research context, and then narrowing your focus to identify specifically what you plan to do in the paper: i.e., your research objectives. The research objectives are then formulated into research questions. Research objectives and research questions should be placed in the Introduction section. However, a common mistake that authors make is to present a full review of the literature in their field. What is necessary is to mention those aspects that are needed to contextualize the problem that your study is solving.

Literature Review is another key factor because a review of the literature gives a theoretical basis for the research and helps you determine the nature of your own research. The research objectives and the research questions should provide a way to organize the literature into three parts; some is centrally relevant, some is generally relevant and some is background literature (Punch, 2006). Common mistakes that authors make are to only write a brief review and to merely summarise the literature. Thus, as you review the existing literature, you need to identify any limitations, deficiencies, or gaps in existing knowledge or practice that need to be addressed. In other words, the journal editor expects authors to critically evaluate, reorganize and synthesize the work of others. This process will lead to authors identifying, describing and justifying how their research fits into the existing body of knowledge. In addition, authors should not just cite past studies which yielded positive results, but also make reference to past studies which did not report positive findings. Authors should show that they know the subject matter very well, which is demonstrated through a thorough review of literature. Consequently, a literature review should reach some conclusion on the current state of knowledge in an area, and suggest the next step in the investigation of the problem or question of interest.

Many authors find Discussion section as one of the hardest part to write. A good discussion section should show how authors put together or relate the different findings of the paper together, analyze them in the context of existing literature, offer speculations, suggest further research and highlight the research's contribution and novelty or possible novelty. However, editors reported that Discussion section often contains summary of findings. It lacks evaluative and critical thoughts about how findings are related to the topic or area or the research discipline. Discussion is actually the least rigid part of a paper, hence, authors are or may simply be at a loss as to what to write. Journal editors agree that this section actually demonstrates the author's argumentative, critical and reflective writing skills. Discussion should be supported with reference to theory or theories which framed the present study, and past studies for the purpose of supporting, emphasizing, reiterating or even rebutting the present study with past studies. Past studies can also be used to introduce new ideas. Authors should write in a scholarly tone and avoid using judgemental, biased or emotional language.

The final key point which editor-in-chief seeks is contribution and novelty of the research. Before I go on, is there a difference between the contribution and novelty? Novelty simply means "something that hasn't been done 
before", while "contribution" specifically refers to contribution to the state of the art and solving a problem that has not previously been solved (or solving an old problem better). With the increasing amount of research output, many high impact journals are now seeking highly novel information to publish. Authors must do a thorough literature search to find out what is known and what are the gaps that need to be clarified, which will lead authors to finding the novelty in their respective area of research. Novelty will largely depend on your in-depth knowledge of the field. The novelty of a research can be found in many ways for it does not necessarily entail inventing a new method or technique. Often authors speculate the novelty of the research, instead of stating specifically the novelty. It is alright to speculate about possible applications or the likely impact of the applications. However, these statements are often very general and broad. If you have designed or improved on a method, the readers and the editors want to know what will the method be good for specifically Who or how exactly will it benefit other researchers who may want to use the method? Or you might have employed a wide analysis of a well-known method which leads to contribution in how the particular study can be improved. The employment of this wide analysis may be helpful to improve, for example, a method on analyzing how students write a report. You can therefore, highlight the novelty of the analysis. Explain how this analysis will add to the existing literature. Disproving an existing idea also qualifies as novelty. Authors can incorporate the following strategies in their journal article to demonstrate or show the novelty of the research - (1) highlight the gaps in the Introduction section and mention how your study is going to address any/some of the gaps, (2) discuss the findings of the previous studies in the Discussion section, and specifically mention what new observation or insight was generated through your study results and (3) Mention clearly how your study advances the knowledge in the field.

\section{REJECTION OF JOURNAL ARTICLES}

The key to understanding an article is good writing. Although the research is robust and solve a "big" and relevant problem, poor language will certainly lead to rejection of the article. Language does not only include the structural aspect, but lexical too. In addition, a huge part of writing lies in creating flow of the paper; coherence. This means the reader can easily follow through from one sentence to the other. Editors agree that a badly written paper will be dismissed because they do not understand what the authors are getting at. Based on my experience, if the abstract is peppered with language mistakes, the rest of the paper will have the same problem.

Peter Thrower, the editor-in-chief of Carbon Journal reported that at Elsevier, between $30 \%$ to $50 \%$ percent of articles do not even make it to the peer review process. This is a high percentage of rejection. If the editor-in-chief keeps asking the question 'so what' to himself or herself while reading the article, the possibility of the article being rejected is very high.

Very often, authors do not read the journal's submission guideline, nor the focus and scope of the journal. Failure to adhere to the journal's submission guideline is one of the main factors why the paper is declined. Articles which are not within the focus and scope, or aims of the journal will definitely be rejected. Authors are advised to spend time reading about the journal that they want to submit their papers to and read papers which have been published in the journal.

Other reasons include incomplete paper, which refers to the key points which I have described earlier. Authors fail to establish the introduction well because they do not cite key works in the field and they do not show evidence of extensive reading. Failure to do this will lead to failure to justify the significance of the research. Consequently, the research objectives and research questions are poorly formulated. By reading the introduction, the editor-in-chief can decide if the article has potential for publication or is worth considering. This shows the importance of the Introduction section. When authors fail to write a good and clear Introduction, the rest of the article will be affected. A final point to note is novelty. Editors now seek highly novel research to publish due to the increasing amount of research output.

\section{CONCLUSION}

This paper has thoroughly discussed how to transform research reports into academic publication. Several steps, tips, and tricks need to be given attention by novice researchers and authors so that they can engage with the debate with international audience. They must adhere to the requirements demanded by specific targeted journal editors who run and maintain the quality of the journal. When all of these are well considered, unnecessary rejection can be minimized, and the paper can be processed for further reviews.

\section{REFERENCES}

Allen, M. (ed). 2017. Writing a Discussion Section. The Sage Encyclopedia of Communication Research Methods. https://methods.sagepub.com/reference/the-sage-encyclopedia-ofcommunication-research-methods/i15683.xml

Bryman, A. (2007). The Research Question in Social Research: What is its Role?. International Journal of Social Research Methodology, Vol $10,5-20$.

Farell, Thomas, SC. \& Jessica, I. (2015). Exploring Teachers Beliefs and Classroom Practices Through Reflective Practice: A Case Study. Language Teaching Research, Vol 19 (5), 594-610.

Helen, B. (2012). Review of research into the correspondence between language teachers' stated beliefs and practices. System, 40, 282295

Punch, K. F. (2006). Developing Effective research proposals ( $2^{\text {nd }}$ edition). London: SAGE Publications 
Richardson, V. (2015). Conducting Research on Practice. https://www.researchgate.net/publication/238209087.
Original article in Educational Researcher (June 1994). $10.2307 / 1177027$
DOI:

(1)

